\title{
OS CAMINHOS DO SÍNODO DE MISSOURI NO RIO GRANDE DO SUL: EDUCAÇÃO E RELIGIOSIDADE (1900-1910)
}

DOI: http://dx.doi.org/10.1590/2236-3459/50556

\author{
Patrícia Weiduschadt
}

Universidade Federal de Pelotas, Brasil.

\section{$\cos 8$}

\begin{abstract}
Resumo
Este trabalho tem como objetivo compreender a instalação da instituição luterana do Sínodo de Missouri (1900) e a sua atuação na realidade religiosa e educativa do Rio Grande do Sul. Como aporte conceitual utilizaram-se os conceitos de habitus e de campo, orientados por Pierre Bourdieu, para entender as disposições interiorizadas das comunidades pela consolidação do campo religioso e escolar. As fontes para embasar a pesquisa foram os dois periódicos editados pela instituição: Der Lutheraner e Kirchenblatt. O estudo discorre sobre a constituição do Sínodo, a formação das primeiras comunidades, as disputas com as instituições luteranas concorrentes, o incremento de aspectos doutrinários na formação educacional e a preocupação com a formação de professores e pastores.

Palavras- chave: educação, luteranismo, Sínodo de Missouri.
\end{abstract}

Abstract

THE PATHS OF MISSOURI SYNOD IN RIO GRANDE DO SUL: EDUCATION AND RELIGIOSITY (1900-1910)

This paper aims to understand the settlement of Lutheran institution Synod of Missouri (1900) and its role in the religious and educational reality in Rio Grande do Sul. As conceptual contribution, the concepts of habitus and field adopted by Pierre Bourdieu have been used in order to understand the rules within the communities, internalized by consolidating the religious and scholastic field. The two journals published by the institution - Der Lutheraner and Kirchenblatt - were used as sources to support the research made. The study discourses the constitution of the Synod, the formation of the first communities, the challenges facing other Lutheran institutions competitors, the increment of doctrinal aspects of education and the Synod concerns about the formation of teachers and ministers.

Key-words: Education, Lutheranism, Missouri Synod.

\section{LOS CAMINOS DEL SÍNODO DE MISSOURI EN RIO GRANDE DO SUL: EDUCACIÓN Y RELIGIOSIDAD (1900-1910)}

\section{Resumen}

Este trabajo tiene como objetivo comprender la instalación de la institución luterana del Sínodo Luterano de Missouri (1900) y suya actuación en la realidad religiosa y educativa en RS. Como 
contribución conceptual utilizaran-se los conceptos de habitus y de campo conducidos por Pierre Bourdieu, para entender las disposiciones interiorizadas de las comunidades mediante de la consolidación de la esfera religiosa y la escuelar. Fuentes de apoyo a la investigación fueron las dos revistas editadas por la institución: Der Lutheraner y Kirchenblatt. El estudio analiza la constitución del Sínodo, la formación de las primeras comunidades, las disputas con las concurrentes instituciones luteranas, el aumento de los aspectos doctrinales en la formación educacional y las preocupaciones del Sínodo con la formación de maestros y pastores.

Palabras clave: educación, luteranismo, Sínodo de Missouri.

\section{LES CHEMINS DU SYNODE DU MISSOURI AU RIO GRANDE DO SUL: ÉDUCATION ET RELIGIOSITÉ (1900-1910)}

Résumé

Cet article a pour but comprendre l'installation de l'institution luthérienne du Synode de Missouri (1900) et son actuation dans la réalité au niveau religieux et de l'éducation dans l'état du Rio Grande do Sul, Brésil. Comme contribution conceptuelle, on a utilisé les concepts d'habitus et de champ proposés par Pierre Bourdieu, afin de comprendre les dispositions intériorisées des communautés par moyen de la consolidation des domaines religieux et scolaire. Les sources qui soutiennent la recherche ont été les deux journaux publiés par l'institution: Der Lutheraner et Kirchenblatt. L'étude concerne la constitution du Synode, la formation des premières communautés, les conflits entre les institutions luthériennes concurrentes, l'augmentation des aspects doctrinaux dans la formation éducationnelle et les préoccupations du Synode envers la formation des enseignants et des pasteurs.

Mots-clé: éducation, luthéranisme, Synode de Missouri. 


\section{Introdução}

objetivo deste trabalho é compreender a instalação do Sínodo de Missouri ${ }^{1}$ no Rio Grande do Sul e o seu impacto na atuação educacional das escolas comunitárias. Cabe lembrar que muitas comunidades já tinham organizado as suas escolas e igrejas, por isso o Sínodo investiu no convencimento à filiação dos núcleos constituídos anteriormente a sua fundação.

Neste sentido, os conceitos de habitus e de campo formulados por Pierre Bourdieu (2002; 1996a; 1996b; 1989; 1983), sustentarão teoricamente o trabalho, no intuito de compreender a disposição de ação pela interiorização dos sujeitos e a relação com determinadas situações na ocupação do espaço que instituem um habitus próprio.

O habitus pode ajudar a compreender como o indivíduo se articula no coletivo internalizando disposições. A posição ocupada pelas comunidades facilitou a conquista do Sínodo num jogo de forças buscando angariar os fiéis pelo fortalecimento de um campo religioso diferenciado, o campo religioso doutrinário. Ou seja, o Sínodo se propunha a se autodeclarar como a verdadeira igreja luterana e como instituição que investia na formação docente e pastoral, bem como aquela que dava a devida atenção às suas escolas. Já o conceito de distinção e de legitimidade, defendido também por Bourdieu, pode auxiliar na reflexão da necessidade de convencimento dessas comunidades pelo Sínodo pela proposta de se diferenciar de outras instituições religiosas, utilizando-se de propaganda para justificar a necessidade de investimento educacional e doutrinário.

As fontes utilizadas foram os jornais Der Lutheraner e Kirchenblatt, publicações organizadas pelo Sínodo (1895-1920). Der Lutheraner, jornal publicado nos Estados Unidos, em meados do século 19, em alemão gótico com distribuição mundial, também distribuído no Brasil. Kirchenblatt, jornal fundado em 1903 pelo Sínodo no Brasil, em Porto Alegre. Os dois jornais, um a nível internacional, outro local, apresentavam textos informativos do trabalho do Sínodo, propagandas do sistema educacional dos seminários nos Estados Unidos e no Brasil, textos doutrinários aprofundados e relatórios das localidades de atuação do Sínodo. Por isso, as fontes são elucidativas para entender o processo educacional, com as devidas problematizações e limitações que a cercam, visto que essas fontes foram produzidas pelo próprio Sínodo. Na primeira parte do artigo serão apresentados os caminhos da instalação do Sínodo na região meridional do Rio Grande do Sul, logo em seguida os dados da formação das primeiras comunidades e depois o fomento da educação doutrinária e o impacto educacional desse trabalho.

\section{Caminhos do Sínodo de Missouri na região meridional}

Ao tentar demarcar uma identidade e um campo religioso, o Sínodo de Missouri foi insistente no processo de instalação no Brasil. Pelas fontes pode-se perceber os caminhos dessa iniciativa, presente desde 1896, mas que efetivamente tomou corpo a partir do início do século 20. O primeiro a contatar com o Sínodo no Brasil foi o pastor

\footnotetext{
${ }^{1}$ O Sínodo de Missouri é uma instituição religiosa luterana originária dos Estados Unidos, fundada por imigrantes alemães fugidos do crescente racionalismo religioso no século 18. Preza por uma ortodoxia e confessionalidade luterana. 
Brutschin, de Estância Velha, este estava descontente com o Sínodo Riograndense ${ }^{2}$. Então ele pediu auxílio ao Sínodo que tão logo enviou um proposto, o pastor Broders, que chegou a Novo Hamburgo, RS, no dia 30 de março de 1900.

Esse foi o primeiro pastor designado para diagnosticar a realidade brasileira. Persistiu no projeto de instalar o Sínodo no Brasil. Nos relatos do Der Lutheraner, as proposições do pastor oscilam entre fatos negativos e positivos para justificar a missão no Brasil. Ele apresenta as resistências de aceitação do Sínodo, mas mostra a urgência do trabalho. Ao mesmo tempo em que demonstrava vantagens de o Sínodo estabelecer-se em terras brasileiras, apresentava as desvantagens no intuito de conseguir um maior auxílio financeiro e administrativo da comissão missionária e dos membros ${ }^{3}$ norteamericanos.

O pastor Broders chegou à região de Estância Velha/RS em 1900. De acordo com os relatos da sua chegada publicados no Der Lutheraner, é mencionada a tentativa de pregação da Palavra e da doutrina do Sínodo como fracassada. Numa reportagem subsequente, Broders retomou a esperança na região rural de Estância Vellha, reforçando as diferenças das pessoas do campo, como sendo estas mais receptivas e concentradas. Muitas delas choraram no sermão proferido por ele. Por outro lado, mantinham costumes que desagradavam a doutrina do Sínodo. Outro dado preocupante era a convivência de pessoas que possuíam credos e posições diferentes como, por exemplo, as relações dos evangélicos do Sínodo Riograndense com a Maçonaria (Der Lutheraner, 7 ago. 1900, ano 56, n. 16, p. 244).

Broders reforçou que o poder pastoral não era tão grande, pois as comunidades gozavam de autonomia administrativa em relação à igreja. Para ele era difícil aceitar essa situação e teria percebido que, além de a igreja, seria preciso motivar as comunidades a uma perspectiva teológica pedagógica diferenciada, instaurando um novo habitus. Nessa realidade cada pastor adaptava-se com o contexto encontrado e contentava-se com o salário recebido, ou seja, as pessoas estavam acostumadas a compartilhar a igreja como mais um espaço de sociabilidade e não habituadas a seguir compromissos doutrinários.

Em contrapartida, no final da mesma reportagem continuava o alerta e a incerteza do trabalho de missão do Sínodo:

Mesmo assim, não esqueçam que este relato é um prenúncio que o $P$. Broders nos contou. Ele fará outras incursões missionárias no Brasil. Apesar de tudo isto, nós devemos pensar que debaixo desta indiferença religiosa, ainda assim, o evangelho tem poder e pode fazer as pessoas voltarem e se redimirem. Nós norte americanos alemães não somos melhores que os sul americanos, nós temos que agradecer que aqui

\footnotetext{
${ }^{2}$ Instituição luterana concorrente do Sínodo de Missouri. Já havia sido organizada nas comunidades alemãs em meados do século 19 (Dreher, 2002; 2000).

${ }^{3}$ Membro da comunidade é um termo utilizado comumente pelo meio luterano, significa que os membros fazem parte de uma instituição. O Sínodo de Missouri, em suas orientações doutrinárias, enfatiza que Cristo é a cabeça e os participantes são os membros. Legitimados especialmente pelos seguintes versículos: "Porque, assim como em um só corpo temos várias partes, e todas elas têm funções diferentes, assim, também nós, embora sejamos muitos, somos um só corpo por estarmos unidos com Cristo (Romanos 12, 4). "Portanto, vocês são o corpo de Cristo, e cada um é uma parte desse corpo" (I Coríntios 12, 27. Bíblia na Linguagem de hoje, 2005).
} 
conosco existem outros costumes. Que a graça de nossos pais desde 60 anos atrás nos trouxeram uma pregação correta do Evangelho e que nossas crianças, filhos e netos até esses dias permanecem fiéis. (Der Lutheraner, 7 ago. 1900, ano 56, n. 16, p. 246)

A Comissão Missionária, usando o periódico como propaganda, apontava que a causa da indiferença religiosa não estava nas pessoas, mas na falta do conhecimento da verdadeira doutrina. Ao afirmarem que as pessoas da América do Sul eram alemãs, poderia ser vantajoso este alinhamento étnico. De certa forma este fato parecia encorajar o trabalho de missão. Daí a dificuldade de entender certas práticas dos descendentes germânicos que não eram aceitas pelo Sínodo. Cabe ressaltar que muitos dos costumes dos descendentes germânicos já se haviam modificado. Na própria condição de imigrante, as relações frente às tradições não permaneciam iguais às da Alemanha ou às de imigrantes alemães estabelecidos nos Estados Unidos desde o século 18.

Ao diagnosticar a possibilidade deste projeto, o pastor Broders não enxergava, num primeiro momento, meios de alcançar estes objetivos devido à realidade mostrada. Por isto, o surgimento de uma comunidade que quisesse aceitar o Sínodo foi importante para o desenvolvimento dessa instituição no Brasil. Otto Beer (1925), comentou a história do Sínodo em uma das obras sobre o seu surgimento no Brasil:

No sul do Estado, na região de Pelotas e São Lourenço, existia uma grande organização alemã. O Sínodo Evangélico (Sínodo Riograndense) tinha descuidado e não vinha ocupando pastoralmente a região. Os assim chamados pseudopastores agiam ativamente na área. Aqui estavam radicados mais de 10.000 pomeranos e alemães da Renânia. Com o decorrer dos anos, organizaram-se entre eles cerca de 30 sociedades escolares que também assumiam caráter de comunidades. (Beer, 1925, p. 22)

Ao chegar à região de Pelotas, especificamente na Colônia São Pedro, Broders conversou com um morador, August Gowert, que aceitou os préstimos do pastor. Então, no dia $1^{\circ}$ de julho de 1900 , foi fundada a primeira comunidade do Sínodo de Missouri na América do Sul (Beer, 1925). Logo depois, o pastor Broders começou a propaganda pelas colônias da região meridional do Rio Grande do Sul, no interior de Pelotas e São Lourenço do Sul, onde grande parte desses colonos eram de descendência pomerana.

August Gowert agradou-se do trabalho doutrinário do Sínodo. Ele preocupou-se com a origem confessional da instituição de Broders e questionou-o acerca de fundamentos teológicos ${ }^{4}$ (Warth, 1979, Rieth; 1990).

Ainda no Der Lutheraner, Broders mencionou a esperança de formar uma comunidade luterana no interior de Pelotas. Na reportagem intitulada Uma experiência compartilhada no Brasil admitia-se que na instalação poderia haver muitos pontos

\footnotetext{
${ }^{4} \mathrm{Em}$ anos posteriores, na revista Kirchenblatt, há um relato sobre o falecimento de Augusto Gowert, apresentando-o como um dos responsáveis pela manutenção do Sínodo no Brasil: "Ele era um daqueles que amavam a palavra de Deus. Mesmo na difícil época que a Boa Nova era rara por aqui, ele assumiu com diligência o papel de sacerdote do lar, suprindo os seus com a palavra de Deus. [...] Ao lado de Deus, foi um dos grandes responsáveis pela igreja manter-se no colo da sã doutrina. Quando o pastor Broders passou pela região, estando em trabalho de pesquisa sobre campos missionários no Estado, demoramos a crer nele, pois recentemente alguns pregadores de seitas haviam passado por aqui. $A$ pessoa indicada para avaliar o teor da pregação e a pessoa de Broders foi o falecido: diante do seu veredicto, todos passaram a confiar no referido pastor" (Kirchenblatt, 15 out. 1911, ano 8, n. 7, p. 52).
} 
contraditórios, por isto demoraria a divulgação da decisão da implantação de um projeto, porque nos relatos anteriores havia "momentos de muita luz, mas de muita escuridão" (Der Lutheraner, 11 dez. 1900, ano 56, n. 25, p 389).

Nessa reportagem ficou confirmada a instalação do Sínodo, por ter encontrado uma comunidade e grupos de pessoas que tinham o verdadeiro compromisso de fundar esta igreja luterana,

pois, felizes são as notícias do pastor Broders nas últimas cartas enviadas para missão. Na sua viagem missionária Deus o levou onde há uma maravilhosa esperança de sucesso. Com muita alegria, ele escreve em sua carta no dia 2 de julho as palavras em inglês: "I struck oil, some the finest quality" (Achei petróleo e da mais fina qualidade). A gente pode imaginar a alegria do nosso missionário. Pois, em outras tantas ocasiões foram funestos os resultados que o desanimavam. Agora Deus o colocou no lugar certo onde fundou a primeira congregação verdadeira evangélica luterana composta de 17 famílias. As 17 famílias, na grande maioria eram pomeranas, assim como o pastor Broders relata. 10 mil pessoas, a maioria são pomeranas na região. E quatro famílias são os mais refinados teuto russos. Essas quatro famílias tinham o costume de cada domingo ter um culto de leitura, enquanto nos outros relatórios o pastor Broders queixavase das lojas maçônicas e associações devoradoras. Assim relata que neste local há esperanças: Não há nenhum maçônico!" (Der Lutheraner, 11 dez. 1900 , ano 56 , n. 25, p. 389)

Nesse contexto, o pastor Broders afirmou ter encontrado pessoas afinadas com o projeto do Sínodo. A região encontrada era o interior de Pelotas, a comunidade de São Pedro, entre os pomeranos. Esse grupo parecia seguir princípios religiosos parecidos com os do Sínodo. Broders os descreve com os de mais alta qualidade e destaca que estavam dispostos a aceitar a verdadeira fé luterana. Não havia possibilidades de aceitarem uma doutrina diferente como a maçonaria, por exemplo ${ }^{5}$.

No ano seguinte, em 1901, os relatos de Broders acentuam o trabalho de missão e a necessidade de ampliar a igreja e a instituição do Missouri:

A palavra viva será somente vencedora no Brasil se as pessoas não deixarem se enganar. A comunidade de São Pedro é um testemunho fiel. Nós conseguimos desviar as pessoas da maldade. O nosso Sínodo e o nosso trabalho é uma boa nova para o povo do Brasil. Que continue a existir amáveis cristãos na América do Norte que enviam missionários para o Brasil a fim de enviá-los a uma comunidade cristã. Que continue existir luteranos na América do Norte e que desinteressadamente querem trazer aos sul americanos as boas coisas, mesmo que para alguns causem estranheza. Eles não tinham aprendido a Palavra de Deus, não havia sido introduzido o catecismo, não Ihes foi explicado nenhuma história bíblica. Paciência e sacrifício devem prover os missionários, que se colocam a serviço do Senhor e realizam a tarefa para tal trabalho entre os brasileiros

\footnotetext{
${ }^{5}$ A maçonaria era uma grande preocupação para Broders, especialmente quando ele esteve na região norte do Estado e impressionou-se com a aceitação e o convívio entre maçons e os adeptos do Sínodo Riograndense. Não era possível, na concepção de um teólogo do Sínodo de Missouri aceitar essa tolerância religiosa. Por isso ele relata no Der Lutheraner: "Como se encontra no Sínodo Evangélico homens tão negros? Eles vão de mão em mão e mantém suas lojas. Inclusive um destes pastores é um mestre de cadeiras. A comunidade do presidente do Sínodo Evangélico e a cerimônia estão repletas desses irmãos. Morre um católico que era maçônico e o pastor evangélico dá a mensagem fúnebre e o mestre de cadeira se deixa envolver" (Der Lutheraner, 7 ago. 1900, ano 56, n. 16, p. 246).
} 
de descendência alemã de livre e boa vontade. Que Deus nos presenteie com tais homens. Os nossos irmãos sul americanos venham a nós, precisamos adotá-los, eles nos clamam: 'Venham para cá e nos ajudem, nós queremos seguir com o velho Deus que nos abriu os olhos' (Der Lutheraner, 25 ago. 1901, ano 57, n. 13, p. 197)

Pode-se perceber que o Sínodo demonstrava necessidade de se investir no Brasil, por pessoas capacitadas. A justificativa da missão consistia em fazer um trabalho direcionado para a verdadeira fé luterana. Nessa reportagem aparece o apelo para que missionários venham ao Brasil para poder auxiliar neste projeto. Para a igreja fortalecerse era necessário investir nos ensinamentos da Bíblia e de cunho doutrinário e, para isto acontecer, era preciso um projeto educacional. Daí o relato chamar atenção para o cuidado no aprendizado da religião, até mesmo como diferencial no trabalho em relação as outras instituições religiosas luteranas no Brasil.

O Sínodo desmerece os outros trabalhos religiosos, autodenominando-se como a única fonte e verdadeira igreja cristã. Insiste no chamado de outros missionários prometendo bons frutos nas comunidades brasileiras. Apela para o compromisso da igreja norte-americana na condução de pessoas que não tiveram oportunidades e acesso ao verdadeiro conhecimento.

No relato Uma vigem missionária pelo Brasil, do ano de 1901, Broders seguiu comentando o trajeto nas comunidades vizinhas de São Pedro, que formaram as primeiras comunidades do Sínodo de Missouri no Brasil. Comentou que foi com um guia, a cavalo, pelas picadas de Santa Helena, Santa Coleta, nas divisas de São Lourenço do Sul e Pelotas, tentando conseguir mais comunidades ao Sínodo. A sua metodologia era visitar as comunidades, algumas já estabelecidas como religiosas independentes ${ }^{6}$, e propor a filiação ao Sínodo.

Entretanto, os conflitos e tensões apareciam. Broders falava da desconfiança por ele ser norte-americano. Também havia dificuldades nas comunidades, por elas já terem sido enganadas por falsos pastores. As pessoas tinham receio em filiar-se a um Sínodo oficial. Mas mesmo assim ele acreditava que a missão só iria dar certo se houvesse ajuda de mais missionários para o Brasil:

Verdadeiramente o campo está aberto para a colheita, mas poucos são os trabalhadores. Quando doutrinarmos as pessoas e elas se filiarem ao Sínodo, quão fácil será a missão e como será diferente a vida das famílias e das comunidades. Nós devemos nos chocar com essas comunidades que têm estes cura d'almas falsos? Devemos nós luteranos que temos a palavra pura de Deus e sem falsidade deixar esta situação no vento? Não temos nenhuma responsabilidade com estes pobres irmãos da fé continuem com esta situação? Deveríamos nós deixar mais de centenas de almas continuarem sendo enganadas com profetas falsos e deixá-las nas suas necessidades espirituais sem que nós não dobremos as nossas mãos. Dê-te mesmo alento a tuas palavras. Seu missionário! Broders! (Der Lutheraner, 25 ago. 1901, ano 57, n. 13, p. 197)

\footnotetext{
${ }^{6}$ Essas comunidades eram consideradas independentes luteranas, ou seja, no processo imigratório fizeram questão de não participar de nenhuma organização religiosa oficial, por acreditarem que as suas comunidades buscavam a religiosidade apenas para o cumprimento dos ritos - batismo, confirmação, casamento, funerais - e pelas escolas comunitárias. Buscavam escapar do domínio religioso devido à experiências na Alemanha, em função da Igreja alemã estatal auxiliar na dominação dos menos favorecidos, que mais tarde, tornaram-se imigrantes. Para saber mais ver em Teichmann (1996).
} 
A insistência em chamar outras pessoas previa o fortalecimento do campo missionário no Brasil. $O$ argumento fundamental era livrar as comunidades das falsas palavras e das pessoas que poderiam prejudicar os grupos na perda de valores religiosos fundamentais.

O trabalho inicia-se nas comunidades da região sul pelo envio de pastores e professores missionários. Ao sustentar essas comunidades pomeranas, o Sínodo encorajou-se a investir em outras regiões do Estado.

\section{Primeiras comunidades: formação e disputas}

As primeiras comunidades na região Sul do Rio Grande do Sul, que aceitaram fazer parte do Sínodo de Missouri possuíam as características do movimento imigratório, eram organizadas em pequenas propriedades, a maioria dos seus membros eram agricultores. Mantinham um sistema de agricultura familiar e as famílias, em geral, eram numerosas.

Nos primeiros dois anos de fundação do Sínodo (1900-1902), as comunidades formadas nesta região eram cinco: congregação de São Pedro, localizada no interior de Morro Redondo, na época pertencente a Pelotas, e Morro Redondo, próximo a São Pedro, Santa Coleta e Santa Eulália, interior de Pelotas, e Bom Jesus, interior de São Lourenço do Sul.

Logo a seguir, essas comunidades deram origem às outras comunidades do Sínodo na região meridional do Estado, as quais se formaram no interior de Canguçu, Piratini, Pelotas e São Lourenço do Sul ${ }^{7}$.

Estas primeiras cinco comunidades puderam fortalecer o Sínodo para que em seguida ele pudesse se expandir para outras regiões do Estado. Assim aconteceu a primeira convenção ${ }^{8}$ nacional do Sínodo em 1904, no Rincão de São Pedro, no Noroeste do Estado. Buscou-se ampliar os domínios da instituição fundando comunidades também em Porto Alegre.

A expansão seria inevitável, porque a instituição para crescer não poderia ficar limitada a investir numa região. No Rio Grande do Sul haviam muitas localidades de imigração alemã e isso facilitava a penetração, pois a sua literatura e os processos educativos eram transmitidos na língua alemã:

Em meio a tudo isso, o trabalho do Sínodo de Missúri expandiu-se a outras áreas do Rio Grande do Sul. Como resultado de viagens de Mahler, seus pastores passaram a atuar em comunidades nas regiões noroeste (Rincão dos Vales, hoje Santa Clara do Ingaí) e central (Toropi, Nova Santa Cruz, Jaguari e Rincão de São Pedro do Sul), nas colônias velhas (São Leopoldo, Dois Irmãos, além de Estância Velha, já atendida por Brutschin) e em Porto Alegre. Aqui, foram organizadas comunidade e escola no bairro Navegantes, a Comunidade Cristo e o Colégio Concórdia, integradas por um bom número de imigrantes teuto-russos. Já nos primeiros anos, as instâncias de administração da IELB seriam transferidas para a capital. (Rieth, 1990, p. 264).

\footnotetext{
${ }^{7}$ Recentemente, as comunidades que deram início ao Sínodo estão integradas em dois distritos: Distrito Sul I e Distrito Sul II, contando com 6169 e 9126 integrantes, respectivamente, segundo dados estatísticos do Anuário 2005 da lelb, apontando a reunião de fiéis dos dois distritos como um dos maiores da lelb.

${ }^{8}$ As convenções eram reuniões entre as comunidades, podiam ser nacionais, envolvendo todos os pastores e alguns representantes das comunidades, e também regionais, organizadas por localidades próximas, denominados distritos. Ainda é uma prática utilizada pela IELB.
} 
Apesar de o foco do estudo centrar-se nas comunidades pomeranas da região Sul, acredita-se ser importante apresentar as demais comunidades que foram criadas quase num mesmo período para entender melhor a instalação desta organização.

De acordo com relatos do Kirchenblatt, em 1904 pode-se notar a presença do Sínodo na região meridional, bem como em outras regiões do Estado, constando o número de comunidades, escolas, alunos, participantes nos cultos, atuação nos batizados, na confirmação, comunhão, casamentos, sepultamentos, entre outros.

Tabela 1-

Primeiros números das comunidades e escolas do Sínodo de Missouri.

\begin{tabular}{|c|c|c|c|c|c|c|c|c|c|c|c|c|c|c|}
\hline $\begin{array}{l}\text { Nome dos } \\
\text { pastores }\end{array}$ & 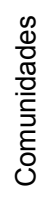 & $\begin{array}{ll}0 & 0 \\
0 & 2 \\
0 & 0 \\
0 & 0 \\
0 & 0 \\
0 & 0\end{array}$ & $\frac{\mathscr{2}}{\mathbb{E}}$ & 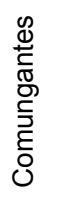 & 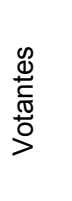 & $\begin{array}{l}\text { \% } \\
\frac{\pi}{0} \\
\text { d } \\
w\end{array}$ & 告 & 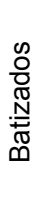 & 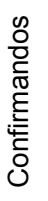 & 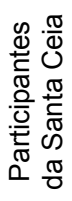 & 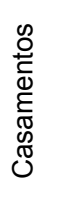 & 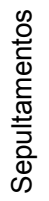 & Anotações & $\begin{array}{l}\text { Nome das } \\
\text { comunidades }\end{array}$ \\
\hline $\begin{array}{l}\mathrm{J} . \\
\text { Hartmeister }\end{array}$ & 1 & -- & 240 & 143 & 35 & 1 & 26 & 15 & 8 & 141 & -- & 2 & $\begin{array}{l}4 \text { alunos jovens vão } \\
\text { ser preparados para } \\
\text { a escola eclesiástica }\end{array}$ & Bom Jesus \\
\hline \multirow{2}{*}{ R. Kern } & 1 & 3 & 331 & 143 & 59 & 1 & 31 & 42 & 20 & 61 & 31 & 5 & $\begin{array}{c}\text { Escolas noturnas } \\
\text { com } 8 \text { alunos }\end{array}$ & Jaguary \\
\hline & 1 & - & 86 & 49 & 15 & 1 & 9 & 6 & 4 & 31 & 1 & 1 & $\begin{array}{l}\text { O professor que } \\
\text { atende é um colono }\end{array}$ & Sertão \\
\hline \multirow{3}{*}{ H. A. Klein } & 1 & -- & 160 & 80 & 40 & 1 & 32 & 8 & -- & 13 & 1 & -- & & São Leopoldo \\
\hline & 1 & -- & 120 & 60 & 30 & -- & -- & 4 & -- & -- & - & -- & & Morro Pelado \\
\hline & 1 & -- & 140 & 70 & 35 & 1 & 20 & -- & -- & -- & - & - & $\begin{array}{l}\text { Nesta escola fica um } \\
\text { professor }\end{array}$ & $\begin{array}{l}\text { São Miguel } \\
\text { dos Dois } \\
\text { Irmãos }\end{array}$ \\
\hline W. Moller & 1 & 2 & 300 & 100 & 47 & 1 & 28 & 35 & 11 & 49 & -- & 3 & & Toropy \\
\hline $\begin{array}{l}\text { R. Mueller } \\
\text { W. Mahller }\end{array}$ & 1 & -- & 120 & 67 & 28 & 1 & 110 & 34 & -- & 69 & -- & 13 & $\begin{array}{c}\text { A escola diária tem } \\
\text { duas classes. } \\
\text { Escola noturna: } 26 \\
\text { Escolas dominicais: } \\
35\end{array}$ & Porto Alegre \\
\hline E. Schultz & 1 & - & 130 & 70 & 20 & 1 & 32 & 8 & 8 & 58 & 1 & 1 & & São Pedro \\
\hline H. Stiemke & 1 & - & 179 & 74 & 25 & 2 & 30 & 20 & 7 & 45 & 2 & 5 & $\begin{array}{l}\text { Ali uma só vez foi } \\
\text { pregado } \\
\text { Números da escola } \\
\text { falhos }\end{array}$ & Santa Eulália \\
\hline \multirow[t]{2}{*}{ A.Vogel } & 1 & -- & 180 & 60 & 19 & 1 & 29 & 12 & 8 & 96 & 1 & 4 & $\begin{array}{l}\text { No inverno escola } \\
\text { noturna duas vezes } \\
\text { por semana }\end{array}$ & Santa Colleta \\
\hline & - & 1 & 35 & -- & -- & -- & -- & 3 & -- & 33 & -- & -- & & \\
\hline \multirow[t]{2}{*}{ H. Wittrock } & 1 & -- & 105 & 54 & 17 & 1 & 22 & 12 & 11 & 27 & -- & 1 & & $\begin{array}{l}\text { Rincão dos } \\
\text { Valles }\end{array}$ \\
\hline & 1 & -- & 100 & 45 & 17 & 1 & 12 & 13 & 5 & 32 & 1 & -- & $\begin{array}{l}\text { Nesta escola tem um } \\
\text { professor auxiliar }\end{array}$ & Osório \\
\hline
\end{tabular}

Fonte: Kirchenblatt, $1^{\circ}$ fev. 1904 , ano 1, n. 7, p. 50. 
Como se observa na tabela, as comunidades de Bom Jesus, São Pedro, Santa Eulália e Santa Coleta, e as de outra região, estão destacadas pelas atividades desenvolvidas pelo Sínodo. Nota-se uma preocupação da organização do Missouri em mencionar os dados estatísticos do começo de suas comunidades.

Chama atenção à presença escolar com o número de alunos, bem como dados sobre a escola nas anotações. Nessas anotações as informações são referentes aos problemas das escolas. Evidencia-se, assim, uma carência de professores para atuar nas escolas. Na comunidade de Bom Jesus o destaque ficou para o seminário que estava preparando, na época, quatro jovens. Em Santa Eulália os trabalhos não eram realizados com muita regularidade, sendo que esta comunidade, atualmente, não pertence ao Sínodo. Ainda São Pedro e Santa Coleta aparecem na relação de escolas, sendo que esta última contava com uma escola noturna, provavelmente para alunos adultos. A única comunidade que não aparece nos dados estatísticos é a de Morro Redondo.

É plausível que as comunidades na tabela estejam organizadas na sua fase inicial, tendo ainda uma comunidade por pastor, alguns pontos de pregação, ou seja, lugares que começavam a se organizar, geralmente nas casas de pessoas interessadas em se filiar ao Sínodo. Esses pastores, que atuaram nestas primeiras comunidades, eram missionários enviados dos Estados Unidos. A maioria delas não se manteve na mesma localidade, por isso a preocupação do Sínodo em formar o mais rápido possível pessoal qualificado.

Comparando as quatro regiões do Rio Grande do Sul - região Sul, região Noroeste, região Norte e a região de Porto Alegre - com comunidades que aderiram ao Sínodo, evidencia-se o destaque das comunidades da região meridional representadas pelas localidades já citadas, que detinham um total de 729 participantes. O total de alunos nas escolas soma o maior número que as outras regiões: 117 alunos nas escolas.

A região Noroeste, a segunda região em que o Sínodo buscou fazer missão, é representada pelas localidades de Jaguary, Sertão e Toropy, e conta com o mesmo número da região sul 717 congregados. Mas o número de alunos cai para 68 crianças nas escolas.

Da mesma forma a região do Vale do Rio dos Sinos, representada pelas localidades de São Leopoldo, Morro Pelado, São Miguel dos Dois Irmãos, Rincão dos Valles e Osório contam com 725 congregados, mas com 96 alunos.

Ao comparar as localidades para tentar visualizar o trabalho do Sínodo e a preocupação com a educação, observa-se o envolvimento destas comunidades da região Sul do RS na escola. A região meridional alavancou o trabalho missionário e educativo da instituição, por fim, as outras regiões somaram-se a este projeto, expandindo-a para todo o Estado.

O número de alunos ainda era maior na região Sul do Estado, talvez pela falta de estrutura nas escolas públicas daquela região ou pelo descrédito das escolas religiosas que se tinham formado anteriormente.

A educação ocupou um lugar central na adesão dos fiéis. Disso não se tem dúvidas, porque as escolas eram organizadas de uma forma que possibilitava uma aproximação entre a igreja e a escolarização.

Outro dado interessante é o da região de Porto Alegre. O número de alunos, que chegou a $110 \mathrm{em}$ apenas uma escola, é quase proporcional ao número de filiados, que 
totalizava a 120. Provavelmente, nessa região, muitos alunos não estavam diretamente ligados ao Sínodo, podendo a vaga na escola ser uma forma de buscar novos fiéis. Nesta região a escola estava num contexto urbano, no qual havia mais mobilidade e diferenciação na aceitação dos fiéis. Deste número de alunos podem-se descontar 61 alunos das escolas noturnas, que eram adultos, e alguns das escolas dominicais ${ }^{9}$, entre os quais estavam incluídas crianças em idade não escolar.

Pode-se observar que o crescimento do Sínodo nas outras atividades estava relacionado com a escolarização e com o aprendizado de elementos que fortaleceriam a igreja, como a capacitação de professores, as escolas noturnas, as dificuldades de se contratar um professor apto em relação aos princípios da igreja, a necessidade de inserir os jovens no rito de confirmação para o aprendizado da doutrina luterana.

O trabalho de expansão das primeiras comunidades apostou na fundação de uma igreja ortodoxa e hierárquica, ou seja, relacionado com os Estados Unidos, prezando a escolarização de seus fiéis com objetivos de educar na doutrina da fé luterana e com pessoal qualificado: os seus pastores e professores precisavam ter uma qualificação pedagógica e teológica adequada.

Além das dificuldades estruturais e humanas na instalação do Sínodo, uma das barreiras era a discordância de trabalho das outras organizações luteranas: as comunidades independentes. Basta lembrar que a maioria das primeiras comunidades do Missouri veio do movimento independentista religioso.

Para tanto, era preciso utilizar mecanismos para alcançar tais seus objetivos. Um deles era sustentar a religiosidade doutrinária pela escola. Daí pode ser compreendido como o campo escolar e religioso estão constituídos neste processo, interligados e tensionados:

\begin{abstract}
A tensão entre as posições, constitutiva da estrutura do campo, é também o que determina sua mudança, através de lutas a propósito de alvos que são eles próprios produzidos por essas lutas; mas, por maior que seja a autonomia do campo, o resultado dessas lutas nunca é completamente independente de fatores externos. Assim, as relações de força entre ' conservadores' e os 'inovadores', os 'ortodoxos' e os 'heréticos', os 'velhos' e os 'novos' (ou os 'modernos') dependem fortemente do estado das lutas externas e do reforço que uns e outros possam encontrar fora. (Bourdieu, 1996a, p. 65).
\end{abstract}

Nesse caso, o campo religioso quer ser detentor de maior força, já que pretende determinar as estruturas dos demais campos. O Sínodo de Missouri, ao querer implantar um projeto de igreja confessional tendo como base o reforço da educação com a igreja, tenta sobrepujar o aspecto religioso sobre as demais esferas, mas não deixa de sofrer influências destas.

Para conseguir fortalecer o campo religioso, era necessário buscar uma diferenciação do que havia sido feito por outras denominações religiosas. Sabe-se que no contexto do Rio Grande do Sul, no final do século 19, as comunidades teuto-brasileiras eram atendidas por pastores livres ou por pastores vinculados ao atual Sínodo

\footnotetext{
9 As escolas dominicais eram práticas das igrejas luteranas, em que se aproveitava a educação das crianças nos cultos a que os adultos assistiam. As crianças de todas as idades, até o momento do rito confirmatório, saíam do culto para assistir, na escola dominical, histórias bíblicas e receber orientação religiosa.
} 
Riograndense, que ainda não era unido, por uma série de divergências teológicas e de condução da vida religiosa nas comunidades. Essas duas instituições religiosas - Sínodo Riograndense e as igrejas independentes - eram as que mais atuavam entre os imigrantes evangélicos alemães. Por isso, o esforço em investir nas escolas e organizálas dentro de um projeto pedagógico específico.

\section{O fomento da educação doutrinária}

O Sínodo, no trabalho de missão, pelos periódicos e documentos, defendeu a posição de ser uma igreja baseada na verdadeira fé luterana. A organização das comunidades, de forma hierárquica, primou por este objetivo.

No primeiro número do Kirchenblatt, jornal fundado no Brasil, aparece a convicção de o Sínodo expandir-se pela missão e de se considerar completamente confessional:

Com nosso trabalho e a ajuda de Deus, almejamos alcançar um alvo bem específico: estabelecer um Sínodo fiel à profissão luterana nesse país. Mesmo se a sua presença for modesta cumprirá a sua missão. Mesmo um pequeno grupo luterano pode, se for fiel, cumprir o seu papel de guardião, defensor e pregador do puro evangelho. A influência de um Sínodo fiel e corajoso, que leva a sério seu chamado, vai além de todas as fronteiras (Kirchenblatt, $1^{\circ}$ nov. 1903, ano 1, n. 1, p. 2)

O objetivo parece ser claro: o Sínodo mantinha preocupação com a missão, em termos de qualidade, não somente em aumentar o número de fiéis. Esses fiéis precisavam ser educados e admoestados na fé e na doutrina verdadeira. Essa educação não era só conhecer a doutrina, mas, também, possuir modos de conduta desejáveis que coincidissem com os preceitos do Sínodo. Não importava para a instituição contar com um número pequeno de adeptos, era necessário que esses se adequassem à doutrina pregada pelo Sínodo. Esta característica era diferente do Sínodo Riograndense, pois fortalecia sua instituição de outro modo, buscava as comunidades e se adaptava num primeiro momento a sua realidade, para depois conseguir a adesão dos fiéis. É possível perceber ainda, na apresentação do Kirchenblatt, a necessidade de divulgar a doutrina do Sínodo de Missouri como algo novo, de forma que as pessoas fossem educadas e formadas naqueles preceitos:

Existem, sim, muitos luteranos no Rio Grande do Sul, mas os pastores que deveriam reunir as congregações, não o fizeram até agora. Agiram de forma infiel, abandonado a sua profissão de fé.[...] Nós, todavia, não permitiremos ser desnorteados por esses fatos; sabemos de antemão que colocaremos nosso jornal à disposição de uma causa oprimida e humilhada. Isto nos dá ainda maior convicção de estar ao lado da causa luterana que está traída, abandonada e oprimida, dando-lhe todo nosso apoio. Queremos tornar o nome 'Luterano' novamente conhecido e utilizado. (Kirchenblatt, $1^{\circ}$ nov. 1903 , ano 1, n. 1, p. 1)

O Sínodo faz questão de reforçar que as comunidades ditas evangélicas não podiam considerar-se luteranas, porque não haviam sido preparadas para isto. Organizaram um periódico para divulgação de suas idéias e preceitos, sendo relevante a difusão da educação nas comunidades. 
Entretanto, nem sempre era possível a adesão completa dos participantes. O Sínodo Riograndense era criticado pelo Missouri na forma de atendimento, especialmente na despreocupação doutrinária. Entretanto, o Missouri apostava em uma posição mais radical e hierárquica, por isso, precisava contar com pessoas preparadas para o trabalho missionário.

De fato, a preocupação em divulgar a doutrina continuava em relação ao trabalho local das comunidades. Em outro relato do Kirchenblatt foi apresentado um resumo como estava a comunidade de Santa Helena em São Lourenço do Sul, mencionando que "o pastor, falando sobre os membros, afirma que são diligentes, lêem nossos textos, são freqüentes nos cultos e já conhecem a doutrina relativamente bem." (Kirchenblatt, 15 nov. 1904, ano 1, n. 24, p. 188). Percebe-se a importância que era dada ao conhecimento da doutrina e da participação na igreja. Era evidente que o Sínodo pretendia cumprir no seu projeto uma formação doutrinária nos membros.

Daí a necessidade de pessoal qualificado para trabalhar nas comunidades e possibilitar a doutrinação dos fiéis de forma eficiente, tanto na igreja, quanto nas escolas inseridas no Sínodo de Missouri.

\section{Consolidação do campo religioso e escolar}

A formação do campo religioso esteve relacionada com o campo escolar. Uma das estratégias era fortalecer a escola, trabalhando com pessoas capacitadas, ou seja, formadas para estabelecer uma diferenciação em relação a comunidades independentes.

A preocupação foi tão intensa que logo no início do estabelecimento da instituição, no interior do Rio Grande do Sul, foi fundado o primeiro seminário ${ }^{10}$ para professores e pastores. Essa iniciativa pode ser caracterizada como pioneira, porque mesmo com condições precárias de recursos materiais e humanos foi feito um esforço e o seminário abrigou cinco jovens que tiveram uma formação clássica, teológica e pedagógica. Estas foram práticas instauradas dentro deste contexto: diferenciar-se de outras instituições, nem que isto significasse divergências e conflitos, pois os pertencentes ao Missouri eram formados para se sentir fazendo parte da verdadeira igreja luterana. Os princípios de ortodoxia e rigidez doutrinária ficariam garantidos.

As duas principais instituições concorrentes: a igreja independente e o Sínodo Riograndense foram as que tiveram maior relevância na constituição do campo e na delimitação das práticas. Talvez por apresentarem características muito próximas, por se considerarem luteranas e se originarem no contexto da imigração com uma igreja que mantinha uma organização comunitária, os conflitos evidenciam-se na diferenciação pelos detalhes, das minúcias, mesmo o Sínodo de Missouri afirmando que as diferenças doutrinárias e as suas conseqüentes práticas são muito distantes.

O processo das igrejas independentes era visto como um desvio da igreja luterana, já que essas denominações não investiam na formação de pastores e professores nem, tampouco, orientavam os membros de forma sistemática na doutrina religiosa. Para as

\footnotetext{
${ }^{10}$ A análise do seminário foi realizada no período da dissertação e resultou no artigo WEIDUSCHADT, Patrícia; TAMBARA, Elomar. Seminário teológico e pedagógico do Sínodo de Missouri em São Lourenço do Sul - Bom Jesus (1903-1905). In: TAMBARA, Elomar e CORSETTI, Berenice (org.). Instituições formadoras de professores no Rio Grande do Sul. v. 1. Pelotas: Ufpel, 2008, p 189-206.
} 
igrejas consideradas institucionais as pessoas que atuavam nas igrejas independentes eram deslegitimadas, por serem denominados por eles como pseudopastores, ou seja, eram considerados falsos pastores por não possuírem formação teológica adequada.

É interessante notar que a análise de Eliseu Teichmann (1996) parte de que no contexto brasileiro, especificamente no Rio Grande do Sul, o independentismo não se constituiu em contraposição ao Estado brasileiro, mas em decorrência de uma busca de autonomia por parte dos descendentes daqueles que haviam emigrado. A resistência aos sínodos foi forte, tanto ao Sínodo de Missouri, quanto ao Sínodo Riograndense ${ }^{11}$.

Fica evidente que as comunidades livres independentes tiveram um papel significativo no contexto religioso dos pomeranos, representando a maioria de fiéis pomeranos na região de Pelotas e São Lourenço do Sul até os dias atuais ${ }^{12}$.

Quando o Sínodo de Missouri tentou estabelecer-se na região do extremo Sul, algumas comunidades independentes estavam descontentes devido ao despreparo dos pastores ou por terem certo descaso com a vida religiosa. Então, a valorização dessas comunidades em ter uma confessionalidade verdadeiramente luterana servia muitas vezes como um processo de diferenciação.

Em relação ao Sínodo Riograndense percebe-se a diferenciação de confessionalidade e de organização histórica no país. A confessionalidade do Sínodo de Missouri está assentada em princípios bem definidos, como a aceitação irrestrita das Sagradas Escrituras, as Confissões reunidas no Livro de Concórdia.

Entretanto, o Sínodo Riograndense, que foi pioneiro no contexto de imigração, para conseguir certa unidade entre as comunidades, flexibilizou a aceitação de diferentes vertentes teológicas, assim pretendiam conseguir adesão de mais comunidades.

Analisando comparativamente os dois Sínodos, especialmente na constituição histórica dessas organizações, fica claro que o Sínodo de Missouri buscava inserir-se nas comunidades num projeto hierarquizado, ou seja, pela matriz dos Estados Unidos organizar-se-iam as igrejas e escolas nos seus pontos missionários de acordo com seus preceitos, daí seria necessário constituir-se como uma base confessional forte. Já no Sínodo Riograndense a base da constituição das comunidades era pelo convívio entre igreja e membros. Cada pastor adaptava as doutrinas à realidade encontrada nas comunidades.

As duas instituições sinodais que mais influenciaram a difusão do luteranismo no Rio Grande do Sul tiveram perdas e ganhos com a solidificação da identidade confessional. A indefinição confessional do Sínodo Riograndense proporcionou uma autonomia maior dos pastores, mas, em contrapartida, esta forma autônoma desencadeava alguns descontentamentos.

${ }^{11} \mathrm{Em}$ relação ao Sínodo Riograndense os conflitos com as organizações consideradas independentes também foi grande. Segundo Osmar Witt (1990, p. 290), em 1891, em uma Assembléia em São Sebastião do Caí, o Sínodo Riograndense criou o cargo de pastore itinerante, ou seja, pastores que iriam nas comunidades atendidas por pseudo-pastores, para tentar convencer os membros a aceitar os préstimos do Sínodo. Era uma forma de trabalho que tentava conseguir que as comunidades livres se filiassem ao Sínodo, não impedindo resistências e conflitos entre as instituições.

12 As comunidades independentes mantiveram sua força na região meridional do Estado, como aponta Ricardo Rieth (1990): "Atualmente existem no RS comunidades que se mantém fiéis às origens da maioria das comunidades protestantes criadas até o último quartel do século $\mathrm{XIX}$, que se preservam 'livres', ou seja, sem a vinculação de uma entidade eclesiástica maior. Em sua maioria, localizam-se nos municípios de São Lourenço do Sul, Canguçu, Pelotas e Camaquã, sendo atendidas por mais de 20 pastores-livres" (Rieth, 1990, p. 256). 


\section{Preocupação com a formação de pastores e professores}

A missão do Sínodo de Missouri tinha um projeto claro em expandir a doutrina luterana, baseada em preceitos doutrinários e ortodoxos. A posição da instituição era fortalecer uma igreja que respeitasse os princípios da igreja nos Estados Unidos.

A doutrina só teria sentido se pudesse ser divulgada pelos pastores e professores com formação na própria instituição. Como já foi apontado, nas primeiras tentativas da instalação do Sínodo foi sentida a falta de pessoas capacitadas para o trabalho na igreja. A causa para a situação religiosa entre os evangélicos estar difícil era o trabalho desenvolvido até então:

Deus nos tem dado no Brasil um grande campo missionário. Muitos dos nossos irmãos na fé eram servidos por pessoas perdidas que iam para o erro e deixavam-se conduzir ao desvio e contra os dez mandamentos. Esses companheiros têm usado o ofício de pregadores da reconciliação. Jogaram longe os verdadeiros princípios e mancharam as comunidades. Esses estragadores de alma trouxeram o talar como prova da sua incompetência. (Der Lutheraner, 25 ago. 1901, ano 57, n. 13, p. 197)

Pode-se perceber que o estímulo em ter no Brasil um trabalho proveitoso dependia dos pastores e dos professores que iriam educar e doutrinar as comunidades. A educação para o Sínodo ocupava um lugar central, no sentido de orientar o grupo em que eles estavam inseridos. $O$ relato pretendeu ressaltar o trabalho anterior dos pregadores como irresponsável e sem fundamentação doutrinária. Criticavam que buscam apenas reconciliar as comunidades e se adaptarem a elas para conseguir vantagens. A acusação sobre o trabalho dos pregadores era de eles não terem preparo algum, apenas usarem as vestes pastorais como um símbolo. Também a conduta deles era criticada. Não possuíam uma postura moral adequada para o cargo de pastor. Assim, o relato de Broders no Der Lutheraner busca uma diferenciação e uma legitimação no trabalho missionário:

Se eu fosse um espírito errante e um pregador mentiroso eu pensaria somente em comer e beber, eram assim os exemplos dos pregadores para aquela gente. Se eu tivesse com estas pessoas feito amizades, ali eles teriam me tratado bem. Mas como eu não fiquei ao nível deles, eles me lançaram desafios. A nossa tarefa vai permanecer ao contrário daqueles matadores de almas de pessoas simples que com as almas enganadas acreditam que possam alcançar a graça de Deus. (Der Lutheraner, 25 ago. 1901, ano 57 , n. 13 , p. 197)

A conduta dos pastores que atuavam na época não era tolerada pelo Sínodo. Não admitiam fazer acordos com pessoas despreparadas. Há uma aposta na diferença do trabalho. É preciso ressaltar que a preparação das pessoas era necessária, para atingir objetivos de formação doutrinária e diferentes modos de conduta das comunidades. Era visível que o projeto do Sínodo de Missouri não iria adiante sem o investimento necessário em pastores e professores. Este discurso tinha que ser reconhecido entre os do Sínodo de Missouri, a legitimação desta perspectiva era aceitável, entretanto, entre o grupo a ser conquistado era difícil o reconhecimento e a legitimação. Em estudos de Bourdieu (1996b, p. 112), o autor analisa que a distinção dos grupos precisa ser institucionalizada sendo visível e manifesta: 
Torna-se visível, manifesto, tanto para outros grupos como para si mesmo, atestando a sua existência enquanto grupo conhecido e reconhecido, e afirmando sua pretensão à institucionalização. O mundo social é também representação e vontade; existir socialmente é também ser percebido, aliás, percebido como distinto. (Bourdieu, 1996b, p. 112)

Pode-se analisar as formas como o Sínodo justificou a sua instalação. Destacou-se como um grupo diferenciado dos demais que aqui se encontravam. Não cabe inferir se realmente ele era, mas sim avaliar o que representou a tentativa de se apresentar como distinto, e aí residiu um apelo moral forte na conduta das comunidades, principalmente representada pelo pastor e professor e, logo em seguida, na educação pelas escolas e igrejas. Era necessária a percepção de ser distinto e uma das formas de provar esta distinção era promover uma institucionalização agregada com a formação e organização das comunidades.

Nos primeiros anos o Sínodo perseguiu estes objetivos, relatando nos periódicos o crescimento das comunidades e ressentindo a falta de pastores e professores no trabalho, atribuindo a falta de recursos humanos ao pouco crescimento do trabalho.

Uma prática comum do Sínodo era reunir-se em convenções anuais a fim de debater temas teológicos e pedagógicos, bem como avaliar o trabalho e elaborar um relatório à Comissão Missionária. Na convenção dos dias 6 a 11 de janeiro de 1906, em Toropi, o Sínodo avaliou o trabalho nas comunidades no Rio Grande do Sul. O objetivo principal dessa convenção era a avaliação das primeiras comunidades fundadas. É interessante neste relato a apresentação dos números comparativos do ano de 1903 e 1905, alertando para o fraco número de pessoas para trabalhar como pastores e o crescimento de professores.

Tabela 2 -

Números de membros do Sínodo de Missouri e a relação de pastores.

\begin{tabular}{c|c|c|c}
\hline Ano & Comunidades & Votantes/almas $^{13}$ & N. de pastores \\
\hline 1903 & 23 & $470 / 2758$ & 15 \\
\hline 1905 & 45 & $1300 / 9000$ & 17 \\
\hline
\end{tabular}

Fonte: Der Lutheraner, 10 abr. 1906, ano 62, n. 8, p. 125.

Nota-se que o crescimento das comunidades era considerável e a adesão de novas comunidades era grande. Infelizmente o trabalho dos pastores ficava sobrecarregado, pois só haviam aumentado dois pastores naquele período. Entretanto, em relação à análise dos dados da escola e do número de professores é animador.

\footnotetext{
${ }^{13}$ Nos periódicos do Sínodo, bem como nas atas das comunidades, a diferenciação entre número de votantes e o número de almas era enfatizada. Os votantes eram aqueles que tinham poder de voto nas comunidades. Pelos primeiros estatutos das comunidades as condições para ser votante seria ser homem, ter a maioridade de 21 anos e manter o sustento do lar, ou seja, grande parte dos votantes eram casados. O número de almas refere-se ao total de membros, incluindo crianças, jovens e mulheres.
} 
Tabela 3 -

Números de escolas/alunos do Sínodo de Missouri e a relação de professores.

\begin{tabular}{c|c|c|c}
\hline Ano & $\mathrm{N}^{\circ}$ de escolas & $\mathrm{N}^{\circ}$ de alunos & $\mathrm{N}^{\circ}$ de professores \\
\hline 1903 & 17 & 463 & 5 \\
\hline 1905 & 30 & 900 & 17 \\
\hline
\end{tabular}

Fonte: Der Lutheraner, 10 abr. 1906, ano 62, n. 8, p. 125.

$\mathrm{Na}$ tabela acima ficou constatado que o número de professores triplicou. Mesmo o número dos professores sendo considerado junto com os pastores que acumulavam a função de pastor e professor, fica evidenciado o incremento da atuação na escola. Observa-se que não há uma relação na mesma proporção do aumento do número de alunos. Pode-se inferir que o Sínodo era mais exigente no trabalho pastoral, sendo menos preocupado com a formação dos professores, mas a necessidade de se investir em pessoal capacitado na escola era também importante. O aumento de professores devese, em grande parte, ao acúmulo de funções do pastor em atender à escola. Supõe-se que o acentuado investimento na educação deu bons resultados devido ao aumento dos números dos fiéis. Por isso, o Sínodo segue apelando à Comissão Missionária que envie mais pessoas preparadas:

A necessidade para o trabalho se viu no relatório da missão. Muitas comunidades que esperavam um pastor sozinho tinham que ser consoladas para ter um pastor no futuro. Em especial, faltam dedicados professores para que a juventude possa ser ensinada na verdadeira Palavra de Deus e viva nesta instrução. Também a falha do meio foi profundamente sentida. Que Deus nos dê aos nossos co-irmãos um coração fervoroso para ofertar, que o trabalho que foi muito abençoado não fique arrasado e minado. Que Ele mande mais trabalhadores na sua vinha. Que exatamente nos campos de missão dê esta fidelidade, esta prontidão, de negar a si mesmo e estar junto com o irmão. As dificuldades que devem ser vencidas nos são muito grandes, mas é importante que tenhamos vontade de vencer, não deixando de interceder com os irmãos fiéis. (Der Lutheraner, 10 abr. 1906, ano 62, n. 8, p 125)

De fato, apesar de haver mais professores o relatório denuncia que não havia melhoras visíveis nas escolas do Sínodo. Ainda faltava muito para as comunidades serem fortalecidas e a educação preparar a juventude e as crianças na verdadeira Palavra de Deus. Observa-se que havia resistências por parte do Sínodo em enviar outros pastores ou, talvez, muitos não tinham o desprendimento necessário para abandonar os Estados Unidos e vir ao Brasil.

Em 1909 os relatos no Der Lutheraner chamam a atenção de que o Distrito Sínodo de Missouri crescia, mas no mesmo ano, na Conferência em Santa Cruz, a Comissão de Missão revela que há poucos candidatos dos Estados Unidos a trabalhar no Brasil. A dificuldade no Sínodo sempre foi a falta de professores e pastores. Foram designados seis para o Brasil, só dois aceitaram. Por isso, duas paróquias estavam apreensivas por causa do trabalho distante, elas estavam em perigo estando sem atendimento (Der Lutheraner, 4 maio 1909, ano 65, n. 9, p. 113). É possível verificar que a organização sinodal tinha consciência de que deveriam atender de forma intensiva às suas comunidades, para realmente fortalecer a instituição, conforme seus preceitos. 
Nos anos seguintes o crescimento era maior no número de alunos e fiéis e o número de professores e pastores permanecia estável.

Tabela 4 -

Números de comunidades e pastores do ano de 1909.

\begin{tabular}{c|c|c|c}
\hline Ano & Comunidades & Votantes/Almas & N. de pastores \\
\hline 1909 & 40 & $1519 / 10.000$ & 18 \\
\hline
\end{tabular}

Fonte: Der Lutheraner, 23/03/1909, Ano 65, n. 6, p. 88.

A proporção entre o número de alunos e professores também apresentava falta de profissionais para atuar nas escolas.

Tabela 5 -

Números de alunos e professores do ano de 1909.

\begin{tabular}{c|c|c|c}
\hline Ano & $\mathrm{N}^{\circ}$ de escolas & N. de alunos & N. de professores \\
\hline 1909 & Não consta & 1165 & 18 \\
\hline
\end{tabular}

Fonte: Der Lutheraner, 23 mar. 1909, ano 65, n. 6, p. 88.

Infelizmente não aparece o número de escolas para comparar com os anos anteriores. Nota-se que o aumento de alunos e fiéis foi maior nos primeiros anos entre 1903 e 1905, estabilizando-se em anos posteriores. Uma das possíveis causas seria a falta de pastores e professores para trabalhar de acordo com o pensamento do Sínodo. Vale lembrar que muitos professores são apresentados como auxiliares, ou seja, provavelmente o trabalho na escola ficava por conta do pastor, sobrecarregando-o de tarefas, acarretando, assim, um trabalho mais desgastante, não possibilitando o trabalho intensivo e doutrinário que o Sínodo gostaria de expandir. Dessa forma, foi preciso investir na formação de professores e pastores para a sustentação do trabalho do Sínodo.

Entretanto, nestes primeiros tempos as dificuldades de conseguir professores e pastores são visíveis. Mas o investimento em formação foi constante, com a reabertura do Seminário em Porto Alegre ${ }^{14}$ e o fomento da organização das escolas, edição de material impresso e envolvimento doutrinário com os fiéis.

\section{Considerações finais}

Neste artigo foi privilegiada a gênese do Sínodo de Missouri para a compreensão dos processos que se formaram na sua instalação e as suas pretensões. De acordo com a justificativa da missão no Brasil, considera-se que o Sínodo pretendeu diagnosticar aspectos da realidade brasileira para detectar se havia a possibilidade da instalação do projeto.

Nesse sentido, para o Sínodo, segundo os primeiros relatos, houve muitas dificuldades, pois não era fácil adaptação do Sínodo em relação à realidade dos imigrantes alemães no Brasil e aos valores morais e religiosos das comunidades no

${ }^{14}$ O Seminário foi fechado em Bom Jesus em 1905 e reaberto em Porto Alegre em 1907, funcionando até hoje em São Leopoldo, no Instituto Concórdia. 
Brasil. Mas, ao mesmo tempo em que a religiosidade das colônias de imigração eram consideradas distorcidas, o Sínodo apontava para a necessidade do trabalho, em especial em comunidades que não conheciam a verdadeira doutrina. A instalação se justificava na implantação de um projeto numa comunidade pomerana considerada pura, a comunidade de São Pedro, embora notou-se que, logo em seguida, o Sínodo expandiu o seu trabalho em comunidades independentes na região pomerana e em comunidades de outras regiões do Estado.

Entende-se que o Sínodo buscou encontrar aceitação única nas comunidades, mas, muitas vezes, precisou adaptar-se no seu projeto de missão, buscando adesão em comunidades que já tinham formado a sua organização religiosa pela instalação de pastores e professores qualificados e alinhados com suas bases doutrinárias. Outra justificativa foi a necessidade de se firmar, representando-se como uma instituição considerada a verdadeira igreja luterana. Para isto foi preciso reinventar a tradição existente, descaracterizando as outras instituições religiosas, não as considerando como igrejas legítimas, em função de elas não terem uma doutrina coesa e hierarquizada, e, por fim, era importante fazer os participantes da igreja do Sínodo de Missouri conhecerem a doutrina, absorvendo os ritos e os modos de conduta adequados a esta orientação doutrinária. Assim, o Sínodo demarcou um campo religioso e buscou instaurar um habitus no qual pudesse interiorizar essas práticas.

A partir dessas justificativas o Sínodo percorreu os caminhos para a sua instalação. Algumas comunidades aceitam as orientações das instituições. Porém, dentro das comunidades não havia unidade na aceitação. Nesse sentido, a formação dessa instituição perpassou com conflitos e com tentativas de buscar mais fiéis. O Sínodo, então, entrou em conflito com as outras instituições religiosas: as comunidades independentes e o Sínodo Riograndense. A primeira instituição era criticada pela não formação cristã e secular dos seus orientadores: os professores e pastores. Rechaçavam esta instituição, mostrando o seu líder espiritual como um pseudopastor, numa nítida visão pejorativa em que denotava não ser considerado um pastor legítimo. Com a segunda instituição a crítica foi em relação à indefinição confessional e à falta de orientação nas suas comunidades a uma doutrina clara e de acordo com os princípios luteranos. Essas duas instituições consideradas luteranas foram as que rivalizaram com o Sínodo na demarcação de um campo religioso.

Para a legitimação como verdadeira igreja luterana não bastava o Sínodo se enxergar como tal. Precisava convencer as comunidades. Uma das formas encontradas era a preocupação que o Sínodo tinha em relação à educação. Uma educação doutrinária foi expandida pela organização escolar. Apesar dessas comunidades já possuírem uma organização escolar anterior à instalação do Sínodo, a instituição ofereceu uma educação dita por eles como diferente.

A educação necessitava de pessoal qualificado. As escolas ligadas ao Sínodo de Missouri não poderiam ter professores sem formação nem, tampouco, ter nas igrejas, pastores sem formação teológica. Por isso, num primeiro momento, o Sínodo, trouxe seus pastores e professores dos Estados Unidos, todos com formação específica, formados nos seminários norte-americanos, mas ressentiu-se da falta de pessoal para trabalhar nas comunidades inseridas no Sínodo. Nesse ponto, o Sínodo não podia atender sem pessoal qualificado, pois precisava ser diferente das outras instituições nem, tampouco, podia 
aceitar qualquer pastor ou professor. No início, o Sínodo pediu à Comissão de Missão mais obreiros para trabalhar no Brasil, mas, de acordo com os dados, o números de alunos, escolas e igrejas aumentou, permanecendo com quase o mesmo número de professores e pastores. Como o seu trabalho de missão buscava ser intensivo, ou seja, o pastor e professor buscavam melhorar o trabalho, mas a situação agravava-se com a falta de formação teológica-pedagógica.

Por isso, o Sínodo precisou continuar investindo na preparação de pastores e professores, bem como necessitou ampliar a publicação e circulação de material impresso e fortalecer a organização no Brasil pela interlocução do campo escolar e religioso.

\section{Referências}

ANUÁRIO LUTERANO. Igreja Evangélica Luterana do Brasil. Cristo para Todos. Porto Alegre: Concórdia, 2005.

BEER, Otto. 25 Jaher unter dem Sudlichen Kreutz (1900-1925). Porto Alegre: Concórdia, 1925.

BOURDIEU, Pierre. A Economia das trocas lingüísticas: o que falar e o que dizer. São Paulo: USP, 1996b.

BOURDIEU, Pierre. O poder simbólico. Lisboa: Difel, Bertrand Brasil, 1989.

BOURDIEU, Pierre. Pierre Bourdieu entrevistado por Maria Andréa Loyola. Rio de Janeiro: Uerj, 2002.

BOURDIEU, Pierre. Questões de sociologia. Rio de Janeiro: Marco Zero, 1983.

BOURDIEU, Pierre. Razões Práticas sobre a teoria da ação. Campinas: Papirus, 1996a.

DER LUTHERANER. St Louis, Concordia Publishing House, 1899-1915. Revista Oficial da The Lutheran Church Missouri Synod (EUA)

DREHER, Martin (org.). 500 anos de Brasil e Igreja na América meridional. São Leopoldo: EST, 2002.

DREHER, Martin N. Notas para uma história da educação protestante no Brasil. Estudos Leopoldenses, v. 4, n. 6, 2000, p.133-150.

EVANGELISCH. Lutherisches Kirchenblatt Sued-Amerika, Porto Alegre, 1903-1904; 19081913- Revista Oficial da Igreja Evangélica Luterana do Brasil.

HOBSBAWN, Eric. A invenção das tradições. Rio de Janeiro: Paz e Terra, 1997.

RIETH, Ricardo W. Protestantismos na América meridional. In: DREHER, Martin (org.). 500 anos de Brasil e Igreja na América Meridional. São Leopoldo: EST, 2002, p. 139-141.

TEICHMANN, Eliseu. Imigração e igreja: as comunidade-livres no contexto da estruturação do luteranismo no Rio Grande do Sul. São Leopoldo: Instituto Ecumênico de Pós Graduação, 1996. 172f. Dissertação (mestrado em Teologia). Programa de Pós Graduação Instituto Ecumênico, EST.

WARTH, Carlos H. Crônicas da igreja: fatos históricos da Igreja Evangélica Luterana do Brasil: 1990-1974. Porto Alegre: Concórdia, 1979.

WEIDUSCHADT, Patrícia; TAMBARA, Elomar. Seminário teológico e pedagógico do Sínodo de Missouri em São Lourenço do Sul- Bom Jesus ( 1903-1905). In: TAMBARA, Elomar; CORSETTI, Berenice (org.). Instituições formadoras de professores no Rio Grande do Sul. V. 1. Pelotas: Ufpel, 2008, p. 189-206. 
WITT, Osmar Luiz. Igreja na Imigração: o Sínodo Rio-Grandense e o acompanhamento de imigrantes. In: DREHER; Martin (org.). Populações rio-grandenses e modelos de igreja. Porto Alegre: São Leopoldo, EST/Sinodal, 1990, p. 281-294.

PATRÍCIA WEIDUSCHADT é professora na Faculdade de Educação da Universidade Federal de Pelotas. Doutora em Educação pela Universidade do Vale dos Sinos. Endereço: Rua Laura de Souza Lang, 321 - 96020-630 - Pelotas - RS - Brasil. E-mail: prweidus@gmail.com.

Recebido em 29 de setembro de 2014.

Aceito em 19 de maio de 2015. 